\title{
EDITORIAL
}

\section{Environment Conservation, International Treaties and Sustainable Development}

The natural environment provides the world with life supporting systems. Plants and trees support life by providing oxygen. Cascading water ways and water bodies with plants and other living beings in them purify and produce water for human consumption. We learn many things from our surrounding environment from the day we are born. Observations of nature has led to scientific discovery and development of technologies. This is called 'Bio-mimicry' which is "an approach to innovation that seeks sustainable solutions to human challenges by emulating nature's time-tested patterns and strategies." A few examples: The aerodynamics of the famous Japanese Bullet train was inspired by the shape of the Kingfisher bird's head and beak, Velcro was born from the observation of the hooks implemented by some plants for the propagation of their seeds via animals.

But today the world environment is facing enormous challenges due to unsustainable rapid economic development. Kofi Annan as the head of UN in 2000 stated that "unequal and human dominated world is ignoring the earth's essential life supporting systems by trying to meet the need of a growing population and Mahatma Gandhi said "there are enough natural resources to meet man's need but not his greed".

With the discovery of fossil fuels, industries revolutionized and production of materials and goods increased rapidly leading to over exploitation of natural resources. Human race became a garbage producing agent. These lead to accumulation of waste all over the world threatening the natural environment. More land areas were cleared for industrial parks, mega agricultural businesses leading to the rapid depletion of the world's forest cover. Synthetic agro- chemicals (fertilizer, insecticides, weedicides etc.) were produced to increase harvest for higher profits and these enhanced pollution of soil, air and water.

Global warming mainly due to increase in GHG in the atmosphere and related climate change have created serious problems all over the world. Temperature increase and erratic weather events are leading to droughts and water scarcity in some parts and flash floods and associated natural disasters in other places. Climate change is considered one of the major global environment problems and it is related to ozone layer depletion, air quality and composition, forestry, biodiversity loss, desertification and interference with the global water cycle.

There are direct and indirect reasons for increasing emission and accumulation of $\mathrm{CO}_{2}$ in the atmosphere. Some of the direct factors are burning fossil fuels, changing land use, raising livestock. Indirect emissions are due to population growth, urbanization, economic development, increased transportation, high energy demand. As urbanization, population growth, enhanced income levels, economic development demand added and increase cooling of industries, workplaces and living spaces more energy has to be used and emission will be enhanced. Air pollution due to transportation and energy generation using fossil fuels, mining, industrial processes, agriculture and waste disposal continue to be increased.

Inter Government Panel on Climate Change (IPCC) was established in 1988 by the WMO and the UNEP to evaluate the risk of climate change. According to the IPCC, $\mathrm{CO}_{2}$ in the atmosphere is expected to reach around 540 to $970 \mathrm{ppm}$ (parts per million) by turn of the century. Carbon Dioxide $\left(\mathrm{CO}_{2}\right)$ concentration in the atmosphere increased from preindustrial value of $280 \mathrm{ppm}$ to over $400 \mathrm{ppm}$ at present. To hold the temperature increase to $2{ }^{\circ} \mathrm{C}$ from preindustrial times, as agreed at Paris Agreement (PA) it is estimated that $\mathrm{CO}_{2}$ concentration in the atmosphere must be maintained at $450 \mathrm{ppm}$ and to be at $1.5^{\circ} \mathrm{C}$ the concentration must be below $350 \mathrm{ppm}$. IPCC estimated that temperature will rise up to $3{ }^{\circ} \mathrm{C}$ to $4{ }^{\circ} \mathrm{C}$ and sea level is expected to rise at least by 0.5 meters by end of this century considering that there is a direct link between atmospheric $\mathrm{CO}_{2}$ and temperature. So it is clear that removal process of $\mathrm{CO}_{2}$ from the atmosphere has to be increased. $\mathrm{CO}_{2}$ emission reduction and increase the forest cover are the main solutions to maintain the $\mathrm{CO}_{2}$ concentration in the atmosphere.

With the industrial revolution synthetic chemicals such as $\mathrm{CFC}$, HFC, HCFC, perfluoromethane, sulphur hexafluoride were manufactured and their Ozone Depleting Potential (ODP) and Global Warming Potential (GWP) are 10,000times higher than that of $\mathrm{CO}_{2}$. Their lifetime in the atmosphere is in the range of thousands of years and therefore their effects on global temperature increase are very high. Ozone in the upper atmosphere absorbs all of Sun's harmful shortwave radiation such as Gamma rays, $\mathrm{X}$-rays and Ultraviolet rays and protects all living beings on the planet earth. If the ozone layer is depleted due to these man-made chemicals, harmful radiation emanating from the Sun will destroy all living animals and plants on the earth surface and even in water bodies.

It was realized that a single nation or group of countries were unable to find solution to remedy this situation mainly because some of the problems were trans-boundary and global in nature. Many of the world organizations such as UN, WHO, WMO, UNEP and international community that deals with humanitarian activities tried to find solutions to these global problems.

Montreal Protocol (MP) on substances that deplete 
the ozone layer (1987), which is the legal instrument of the Vienna Convention to protect the ozone layer (1985), took steps to phase out Chlorofluorocarbons (CFCs) and other Ozone depleting substances (ODSs). In this process, Hydrofluorocarbons(HFCs)andHydrochlorofluorocarbons (HCFCs) were introduced to replace powerful CFC used in the Air Conditioning and Refrigeration ( $\mathrm{AC}$ and Ref.) as well as many other industries. Although HFC is an ozone friendly substance, it has a high Global Warming Potential (GWP). Kigali amendment of Montreal Protocol 2016 proposes to phase down HFC which is used heavily in AC $\&$ Refrigeration industries.

United Nations Framework Convention on Climate Change (UNFCCC) was negotiated and agreed in Rio de Janeiro, Brazil in 1992. Main objective of the UNFCCC is to stabilize GHG concentration in the atmosphere. According to Kyoto Protocol of UNFCCC agreed in 1997, all industrialized countries were to reduce GHG emission by at least $5 \%$ from their emission levels in 1990, during the period 2008 - 2012. PA was negotiated for over 5 years and accepted in 2015 as a remedial measure to failed Kyoto Protocol.

PA is to enhance the implementation of UNFCCC and to strengthen global response to the threat of Climate Change and to help sustainable development and eradicate poverty. PA demand reduce emission of GHGs in order to mitigate climate change. At the negotiation PA further agreed to climate finance of 100 billion dollars a year for developing countries by 2020 , with a commitment to further finance in the future. However only USD 4 billion was pledge up to 2020 .

Sustainable Development (SD) is an essential part of PA. In order to be successful, SD actions need to consider economic, social and economic issues and their inter-linkage. Major aspects that need to achieve SD are environment friendly production and meaningful consumption. Sustainable production is resource efficient and cleaner production and sustainable consumption is intelligent consumption shedding away the emotional related consumption patterns.

Agriculture (production and methods of food preservation), practiced by our ancestors and designing of greener buildings and housing with maximum use of natural lights and ventilation need to be considered. It will be necessary to move away from cooling methods that use heavy equipment more energy and high global warming potential gases (refrigerants). These are some of the areas that can reduce GHG emission and help reduce warming and move towards sustainable development (SD). Moving towards maximum use of renewable alternative energy in long term energy planning will definitely help to achieve SD goals. As expected it is notable that out of 17 SD goals, 8 are human and society focused while only 4 are related to economic development and goals 1 to 7 are directly link to population. Development must be for the benefit of humanity and raise the standard of living. Standard of living is not just driven by pure economic success but it also determine by the quality of the environment one lives in and further it is not the ability of higher consumption.
UNEP recommends strong action is needed now to reduce GHG emission to meet PA goal of holding global warming this century to well below $2^{\circ} \mathrm{C}$ and pursuing $1.5^{\circ} \mathrm{C}$. Reducing emission or mitigation is better than adaptation to climate change which is costly and time consuming. But poor have to adapt for their survival before embark on mitigation. Third world network on January 22, 2021 states that a newly released UN report on "adaptation to climate change impacts", estimates that annual adaptation cost in developing countries are expected to reach USD 140-300 billion in 2030 and USD 280-500 in 2050.

As David Attenborough a naturalist said it's surely our responsibility to do everything within our power to create a planet provide a home not just for us, but for all life on earth at present and for generations to come. Therefore it is paramount important at this stage to educate and create awareness among the world community about the current status of the problem and need for action.

W.L. Sumathipala

The Open University of Sri Lanka \& Ministry of Environment Email:wlsumathipala@hotmail.com 